\section{PSYCHOANALYSIS AND Feminism: Anorexia, the Social World, and the Internal World}

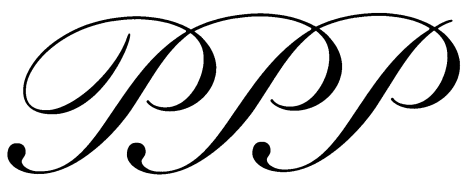

АвsтRACT: This paper discusses the different explanatory approaches taken by feminists and (Kleinian) psychoanalysts to women's psychological illness. In particular, anorexia nervosa (a condition that has attracted much feminist attention) is used as an example. Examination of some Kleinian accounts of work with anorexic patients reveals the great disparity between the terms and focus of psychoanalytical explanation and those invoked in feminist discussions. Can the two perspectives be combined? It is argued that, despite its individualist methodology, psychoanalysis stands to gain from a broader understanding (that feminists might supply) of the cultural "provocation" of psychic conflict. This reconciliation of perspectives would require feminists to go beyond the "common sense" psychology that they often presuppose and to acknowledge the mediating influence of unconscious symbolic significance in experience. In connection with this issue, some work by feminists that has sought to accommodate psychoanalytical ideas is criticized for its "literalism." The lesson to be learned from this discussion applies more widely than to the feminist case.

KEYwORDs: phantasy, internal world, Klein

$\mathrm{I}$ $\mathrm{N}$ THIS PAPER, I pursue one thread drawn from the vast, controversial, and multifaceted topic of feminism's relationship to psychoanalysis. The question I consider is: What, if any, are the possibilities for dialogue between femi-

\section{SARAH RICHMOND}

nists and Kleinian psychoanalysis about the explanation of women's psychological illness? In particular, because it affords such an excellent illustration of the distance that can separate a psychoanalytical perspective from the intuitions, more grounded in common sense, that motivate many feminist analyses, I take anorexia nervosa as my example. ${ }^{1}$ As will become clear, the lessons that can be learned from this investigation are of wider significance, being applicable to all efforts-not just feminist ones-to press psychoanalysis into the service of social theory.

What do I mean by feminist? There are of course many "feminisms" and strong disagreements, relating both to theory and to practice, divide them. It would be foolish to pretend that everyone describing himself or herself as a feminist would subscribe to the sort of analysis I consider here. Rather, the sort of approach I discuss is characteristic of the "liberal" feminist tradition, insofar as it places at the center of its analyses, and seeks to redress, the social and economic inequalities between the sexes. Now, a distinctive aspect of feminist thought-encapsulated by the slogan "the personal is political"has been its insistence that the range of phenomena that require a political analysis needs to be extended. Feminists have theorized areas of ex- 
perience that were formerly thought of as "private" in terms of political, social, and economic structures that constrain women collectively. The analyses of anorexia that I consider here are among the fruits of this effort: disorders that might have been understood as "merely" psychological are regarded instead as a product of the socio-economic structures typical of patriarchal capitalist society.

The epidemiology of eating disorders shows an extraordinarily uneven distribution between the sexes: The ratio of female to male sufferers is around nine to one (Gordon 1990, 32). Further, the onset of these disorders is predominantly in late adolescence and early adulthood. These facts encourage the idea that aspects of the social experience of adolescent and young women play an explanatory role in the onset of anorexia, and feminist suggestions have pursued this line of thought. Thus the importance placed on women's appearance, and the power of the fashion, advertising, and slimming industries are cited as causes of women's excessive anxiety about their shape; while, at the same time, the continued trend of women's lesser earning power reinforces a sense of dependence upon men and a consequent need to "please" them. Factors that relate less directly to the behavior manifest in eating disorders are also cited; here, a suggestion often advanced is that the anorexic becomes obsessed with her food intake and her weight because these are areas that she can control, in stark contrast to the forces with which she contends in the social world. The sexual abuse of women, the insuperable conflicts between the roles (wife/mother/employee) they are expected to play, the subordination of their own needs and schedules to those of other people, are features of women's lives that might explain the drastic sense of psychological heteronomy to which anorexia could appear as a solution. (Dolan and Gitzinger 1994; Fallon, Katzman, and Wooley 1994, Lawrence 1987).

This socio-cultural style of explanation seems worlds apart from that-in terms of childhood experience, unconscious wishes, parental imagos, and psychological defenses-invoked in psychoanalysis. Can a psychoanalytical outlook make any use of feminist insights about contemporary culture, or must the two approaches pass each other by? If a psychoanalyst, as a feminist, believes that sexual inequality in society adversely affects women's mental health, will that belief will be relevant to her work as an analyst?

I consider these questions in relation to Kleinian psychoanalysis, and I examine the accounts given by two Kleinian psychoanalysts of their work with anorexic patients. At first sight, this may seem perverse: Klein's theory has, on the whole, been rejected by feminist theorists and most of those who have turned to psychoanalysis have emphasized their distance from her thought. (A recent wave of feminist interest in Klein, however, has begun to question this negative verdict. See Stonebridge and Phillips 1998, for example.) But this is part of my motivation: It seems to me that the reasons given by feminists for dismissing Klein are faulty, and, in my discussion of her ideas, I try to show why. Klein's work, supplemented by that of the Kleinians who have followed her, develops from and expands upon some of the ideas Freud pursued in his late writings. Kleinian psychanalysis provides a coherent and worked-out account of the mind and of what is involved in psychoanalysis, in relation to which one can consider the questions raised above. Of course, what we learn from the case of Kleinian psychoanalysis will not be generalizable to all psychoanalytical theories, but only by narrowing down questions about psychoanalysis and feminism can they acquire enough determinacy to be answered at all.

I begin by outlining the central ideas in Klein's contribution to psychoanalytical theory, in order to identify the places (if any) at which her account of the development and dynamics of mental life allows for the impact of the social world.

\section{KLEIN’S THEORY}

At the core of Kleinian theory and practice is the idea that the unconscious mind constitutes an "internal world," within which the self is represented as standing in various relationships to its "internal objects." The shape of an individual's internal world determines the possibilities of self-expression available to them, and is, there- 
fore, the key to understanding their personality. Klein (disagreeing with Freud's "primary narcissism" hypothesis) maintained that there are object relations from birth: The human instincts "seek out" the objects they require. A newborn infant, for example, automatically makes for his mother's breast (Klein 1959, 248). But the objects and the nature of our relations with them change dramatically under the weight of early infantile experience-in particular, the experience of being mothered. Klein is explicit about the crucial role this experience plays in shaping psychic development: Without care of a relatively stable and consistent nature, the infant will be unable to advance from its early, highly disintegrated, psychic structure and acquire a more accurate grasp of reality. The theoretical importance of the mother in Klein's thought is unprecedented in psychoanalytical thinking, yet most feminist thinkers who have welcomed this focus have either neglected or explicitly rejected her thought and turned instead to the "objects-relations" school that grew out of it.

Despite Klein's acknowledgement of the developmental influence of environmental factors, feminists have said, pejoratively, that her account is "determinist" (Chodorow 1978, 47, 124), and "short-circuited by her insistence on . . . psychic life as instinctual rather than social" (Eichenbaum and Orbach 1985, 32). I think this is because, in common with so many feminists (and social reformers of other types), they have an exaggerated suspicion of the category of the "innate," and are therefore reluctant to accept Klein's view that environmental factors are not the only determinants of the personality. ${ }^{2}$ For Klein, rather, the newborn infant brings to the world the instinctual nature that characterizes human beings, and the development of the child, and then the adult, is a product of the interaction between "external" influences and the "internal" influence of instinctual forces. (I will have more to say about Chodorow's and Orbach's appropriations of psychoanalysis later).

The instinctual endowment postulated by Klein entails that there is psychic conflict at the heart of our being. Klein, controversially, follows the later Freud in hypothesizing the existence of the "death drive," an innate, destructive force alongside the benign and more creative "libidinal" instinct that Freud had recognized from the outset. In Klein's view, anxiety is not always a response to an external threat; it is stimulated also by the subject's sense of his own aggression and destructiveness (Klein 1946, 4). Prior to any challenge posed by the environment, human beings confront the "internal" challenge, set by their nature, of mastering their own violent instincts and the severe anxiety to which these give rise (Klein 1930, 220). The opposed life and death instincts are discharged onto the infant's objects: The breast that satisfies hunger is represented as a "good," loved breast; in its absence, the hungry infant discharges its aggression on a fantasized "bad," persecuting object. The earliest "objects," then, are represented in terms that are extremely idealized or vilified, according to the instinct they are charged with.

Klein describes the dominant psychic defense mechanisms of the earliest months of life as fantasies of introjection, projection, splitting, and projective identification. ${ }^{3}$ By means of introjection, the infant fantasizes that an object-usually a "good" one-has been installed within his self and is available for his satisfaction. Projection is primarily used to eject "bad" objects outside, either in an attack on an external figure, or merely to expel them from the self. Splitting and projective identification often go together: Typically, the infant may "split" off an intolerable part of his self, and relocate it, in phantasy, in an external object. A cost of this strategy is that the object, understood as the bad self, becomes a source of great persecutory anxiety as the infant fears retaliation from his own alienated impulses. Klein complicates the picture with her account of envy (fully worked out late in her career; see Klein 1957), an emotion to which she accords enormous importance. Envious attacks, discharging the infant's destructiveness, are launched against "good" objects that are perceived to be outside. Again, the prototypical "object" here is the mother's breast, envied because it is both separate and needed, and the infant finds this dependence intolerable.

The experience of being mothered fosters psychic development and integration in a number of 
ways. Through repeated encounters with the mother across time, the infant learns that she is an object that persists and, therefore, that the good and bad breast are not distinct, but aspects of a single entity-a mother who is sometimes obliging, sometimes absent. The "good" and "bad" objects are superseded by more realistic, qualified ones: internalised parental figures, for example, that (in the best scenario), play helpful roles, providing benevolent models for identification. The realization that his mother survives his various attacks makes the infant less afraid of his own aggression, and, in consequence, less inclined to locate it outside himself: This makes for greater integration of parts of the self. Wilfred Bion, in his development of Kleinian theory, suggested that the mother functions as a container for the infant's unbearable feelings: Receiving and understanding the infant's anger and distress, she "returns" them to him in a manageable, more meaningful, form. If the mother is seen in this way, as someone who "feeds" her child psychologically as well as physically, the psychoanalyst will appear to be merely continuing, or perhaps improving upon, this aspect of maternal labor.

In Klein's view, unconscious phantasy, expressing and modifying the states of our internal world, underlies all our conscious mental life and generates its significance. Our choices, actions, and relationships in the "real" world symbolically manifest-in most cases, at least-transactions within our internal world. (In cases of severe psychological difficulty, the capacity of symbolformation may itself be inhibited. The study of such dysfunction has been developed much further, especially through the work of Hanna Segal and Wilfred Bion, since Klein's seminal 1930 paper). For Kleinians, our internal world has primacy in two dimensions: chronologically, insofar as mental life begins with the infant's omnipotent attempts to manage the chaos of its instincts; and explanatorily, insofar as the current state of one's internal world determines the meaning that the "real" world can have. What needs to be emphasized is the extent to which even a roughly accurate grasp of reality is, for Kleinians, a developmental achievement, arrived at by progressive modification of a very crazy starting point. (As most of the infantile fantasies attributed by Klein to her patients confirm. The wildly unrealistic, persecutory phantasy of the "combined parent figure," in which the child's parents are sadistically depicted as engaged in violent, destructive intercourse, injuring each other with teeth, nails, genitals, and so on is a muchdiscussed example [Klein 1932, 200]). Stephen Robinson (intending this comment to be taken as a criticism of Kleinians) aptly sums up their aim: "not to demonstrate how phantasy modifies reality but how reality modifies phantasy" (1984, 180).

The task of a Kleinian analyst is to acquaint the patient (in the face of great resistance) with his internal world. Possession of this knowledge, if it can be had, is therapeutic because it produces in the analysand both a more accurate picture of reality and a more integrated ego: Patterns of projection come to be understood, for example, and the withdrawal of those projections allows parts of the self to be recognized.

\section{The Impact of The Social World}

Klein's account suggests two obvious paths for consideration, in seeking to understand what psychological relevance (if any) it attributes to the social world. On the one hand, thinking in diachronic terms, we can enquire whether Kleinian theory recognizes social conditions as an influence on psychological development; on the other hand, synchronically, we can ask how (if at all) the theory conceives of the impact of "external" situations on an individual at a particular moment.

The first is easily acknowledged by Klein. The mother's influence on the development of the child's object relations is, we have seen, far-reaching. So there are many ways in which the culture she inhabits can determine, "through" her, aspects of the child's personality. The subject of childcare itself is, especially in recent decades, heavily laden with cultural strictures. (And, of course, psychoanalysts have figured among the "experts" whose ideas have shaped the ideology of childcare. In Britain, John Bowlby's and W. D. 
Winnicott's ideas about childrearing were especially popularized and had a wider impact on the public than Klein's [Riley 1983]). The mother's response to her child's needs; her ways of handling, feeding, weaning, toilet-training, and talking to him: all these culturally mediated activities affect the sort of maternal "object" that the child internalizes. Feminists influenced by psychoanalytical theory have emphasized this developmental path and added a suggestion: that, under conditions of sexual inequality, it serves to reproduce invidious sex-based differentiations. Thus Orbach suggests that mothers (often unconsciously) "train" their daughters for future subordination, "directing [them] in gender-appropriate ways," and conveying the message that their “dependency needs" are unacceptable (1993, 24). And Chodorow argues that the current division of parental labor (in which women do virtually all of it) "produces psychological self-definition and capacities appropriate to mothering in women and curtails and inhibits these capacities and this self-definition in men" $(1978,208)$. The theoretical presupposition on which these feminist claims rely-that the mother is a conduit of the social world-is wholly Kleinian; however, Klein's account, we will see, also provides grounds for criticisms of these claims.

The second, synchronic, path-from the external, social world that surrounds an individual to her psychological apprehension of it-is not, for Kleinians, straightforward. Contact with reality is always mediated by the internal world and often distorted by its pressures. The external world signifies only at one "remove," and the object of a psychoanalyst's interest will be the subjective process of its assimilation-its meaning for the patient-rather than reality "in itself." An example provided by Valerie Sinason illustrates this. Her patient, Ahmed (an eightyear old Asian boy) expresses anxiety about the racist attacks that his future stepmother, about to arrive in London, may experience. Sinason, relating this to other comments he has made in the session, discerns underlying feelings of exclusion and displacement aroused by his stepmother's impending arrival. "The external attacks not only cause suffering in their own right but they also add to it, stirring up internal collaborators. Ahmed's jealousy of his new mother's relationship to his father found sadistic solace in seeing the racist stone-throwing re-enacted in his father's wish to see her locked up at home" (Sinason 1989,226$)$. Sinason indicates that the way in which psychoanalysts can help their patients is by pointing out this "internal collaboration": "There is terrible racism in the East End, but had I stayed with the external reality I would not have understood the extra, internal fear of displacement that Ahmed was suffering" (224).

This example suggests that even if social pressures- "terrible racism"- may be acknowledged by an analyst, they do not fall within the concerns of the analysis: Its focus is the patient's internal world. Does Kleinian explanation, then, render a feminist approach to psychopathology, concerned with such "social pressures," otiose? Before we take up this question, let us examine the accounts given by two Kleinian psychoanalysts, Leslie Sohn and Harold Boris, of their work with anorexic patients. ${ }^{4}$

\section{The Psychoanalysis of AnOReXia}

Both Sohn and Boris describe features of the transference of their anorexic (and bulimic) patients in order to make inferences about their object relations. Sohn documents a patient's hypercritical, "spoiling" attitude toward the suggestions put forward in the analytic sessions and sees, in this rejection of his "analytic food,: another version of her anorexic difficulties with "real" food-both of which are to be explained, ultimately, as effects of a disturbed internal relationship. This patient seems, to Sohn, bent on attacking any "giving and sharing of pleasure": The overall picture suggests an internal world in which "an envious attack on the mother and the mother's breast" has occurred, prohibiting the patient from identification with a giving figure and inhibiting any enjoyment from food (or anything else) (Sohn 1985, 52). In his paper, Sohn discusses material drawn from five patients and finds that, despite differences in the severity of the cases, there are some strong similarities: In particular, envy of the breast is found to be a 
central factor in anorexic and bulimic "states of mind," along with various mechanisms that work against the possibility of any awareness of that envy.

Boris, in two papers on anorexia published in 1984 , also finds envy of the mother to be an important factor. In his view, envy can make it impossible for an adolescent daughter to take on a body like her mother's: Her envious attack on the maternal breast deprives her of a good object to identify herself with. Instead, she has only a breast "ruined and deformed by spite" (Boris 1984a, 317). This is the unconscious meaning of the emaciated appearance that the anorexic patient acquires. Boris further suggests that the experience of hunger, sought in anorexia as a constant companion, may serve the defensive function of obliterating any other pain: Anorexic women cannot bear to experience need or want. To dissociate themselves from such feelings, they resort to projective identification. This can be observed in the dynamics of the patients' families: The parents, terrified that their daughter may die, become desperate for her to eat. In this way they take on the "wanting" in her place (316). Boris, like Sohn, emphasizes the difficulty of treating anorexic patients: They tend not to consider their anorexia a problem. Precisely because anorexia provides the patient with a solution to a problem, a "therapeutic alliance" of the kind forged with other patients is extremely difficult to build.

These accounts display a striking convergence: Both involve a difficulty in maternal identification, which is complicated by the patient's early infantile attitudes (especially envy and aggression) toward her mother. Perhaps the symptoms of anorexia (a disorder in eating) suggest the nature of the underlying conflict (rooted in the infantile feeding situation) rather directly. Nonetheless, it is important to note that one cannot generalize in advance about the psychic meaning of all such behaviors. Even if it is likely that anorexia manifests unresolved conflict in an early feeding relationship, other explanations are possible. Psychoanalytical explanation is "finegrained." (Indeed, Boris cautions against jumping to the "obvious" analytical conclusion in the treatment of anorexic patients. He argues that the "oral" conflict so blatantly suggested by their symptoms can serve as a convenient "screen" for later oedipal/sexual conflicts, and that an unconscious rationale for their "wasted" physique may be to complicate the possibility of any sexual response [1984b, 439-40].)

The contrast between the (unconscious) evaluations that, in the psychoanalysts' view, motivate their patients and the more socially informed evaluations that feminist accounts of anorexia invoke is striking. For the analysts, the experiences of puberty and adolescence-especially the biological changes that occur in these stagesforce earlier conflicts to the surface, as the daughter seeks an identification that will underpin her existence as an adult. In the infantile perspective charted by the analysts, the mother appears as an enormously powerful figure whose resources excite envy. Envy harnesses aggression, and, in Boris's view, this is expressed in the anorexic patient's appearance: Her physique, unconsciously, is understood by her to be attacked and damaged. Most feminist accounts of anorexia regard it as a more forward-looking attitude, in direct response to social conditions: For example, the adolescent woman is said to be rejecting the highly unenviable social condition of women in general; and her eating behavior represents, rather than an attack on an individual, a rejection of adulthood (Lawrence 1984).

The psychoanalytical accounts appeal to early, instinct-laden evaluations that float free of current social arrangements and ideological influence: Indeed, it seems quite possible that the same internal situation could obtain in a society that treated women favorably. It is notable that neither analyst appears to regard any of the patients' cultural or socio-economic circumstances as relevant. Boris mentions that self-starvation is a natural way for somebody steeped in guilt to punish themselves and suggests that the fasting rituals of Lent and Yom Kippur manifest, in institutional form, the same idea (1984b, 438). He also hypothesizes that features of contemporary western culture (such as the abundance of food and the preoccupation with slimness) may encourage the "choice" of anorexia as an expres- 
sion of conflicts that might, in other ages, have taken a different turn. (In particular, Boris discerns an "asceticism" in anorexic psychology that would be well suited to some religious and political causes [1984a, 320-21]). But the direction of explanation in these suggestions is from the individual unconscious to the cultural practices. The latter provide a vehicle for the expression of a more universal psychic constellation. ${ }^{5}$

\section{Separate Spheres?}

The psychoanalytical lack of interest in the cultural circumstances of anorexic patients (evidenced in the examples we have examined) may seem to support the conclusion, suggested earlier, that feminist concerns about contemporary socio-cultural conditions will be irrelevant to a psychoanalytical perspective. In the shift of attention, seen in Sinason's example, from the stonethrowing in the street to the internal sadism of her patient, the stone-throwing itself seems to drop out of the picture. Moreover, the accounts given of the motivation of the anorexic patients above, in which infantile impulses and evaluations loom large, are not even compatible with the more immediately intelligible responses to the social world hypothesised by feminists.

Nonetheless, it is a mistake to think that the "internal" and the "social" worlds can be separated out in this way and that it is only the first of the two that engages a psychoanalyst's interest. The internal world is indeed "subjective," structured as it is by the individual's phantasy; but it cannot be contrasted with the "external" world as one might contrast the world of one's imaginings from the world of one's beliefs, because phantasy affects one's perception of, and beliefs about, the external world. As phantasy, according to the Kleinian understanding of the mind, is ineliminable from mental life, it is an illusion to think that a purely "objective" perspective on the world is attainable. This does not entail epistemological relativism however: Phantasy may "interfere" with perception of the external world to a greater or lesser extent, and, as we have seen, it is the analyst's task to bring instances of such interference to the analysand's attention, so that they can be understood. The process involves "triangulation," in which the analyst compares his perceptions with those of the patient; the usefulness of the clinical setting is that it generates shared "external" objects of experience (an analyst's utterances, for example) in relation to which the discrepancy between the patient's and the analyst's perceptions can be displayed. In general, due to his training and the analysis that he has undergone, the analyst's internal world will be the more epistemologically reliable: better able, by virtue of its stability and integration, to underpin an appreciation of the many facets of reality. But on occasion, of course, it may be the analyst's internal world-an aspect of his "counter-transference"-that impedes shared understanding.

The epistemological ideal suggested by Klein's conception of the mind is remarkably similar to that proposed by Nietzsche in his On the Genealogy of Morality, where he insists that the "pure, will-less, painless, timeless, subject of knowledge" must be set aside because

There is only a perspective seeing, only a perspective "knowing"; the more affects we allow to speak about a thing, the more eyes, various eyes we are able to use for the same thing, the more complete will be our "concept" of the thing, our "objectivity." (Nietzsche 1994, 92)

Psychoanalytical investigation includes the "external world," but as it appears to the patient. ${ }^{6}$ What it aims to understand is the perspective within which that world is apprehended by the patient, the significance with which it is imbued.

\section{Social "Provocation"}

If dialogue between feminists and Kleinians is impeded, then, it is not because their spheres of interest do not overlap, but because the terms in which they understand the impact of the external world, and its motivating powers, are too disparate. This suggests that there is a way in which dialogue can be joined, and, indeed, in which a feminist understanding of the social world can supply an important additional component to Kleinian psychoanalysis.

This would require feminists to hand over the task of unearthing an individual's (depth-psy- 
chological) motivation to the psychoanalysts and to embrace the idea that the world signifies symbolically. Their contribution, then-informed by their understanding of social processes-could be an account of the ways in which these processes may force a woman's internal conflicts upon her or block possible modes of escape from them. For example, let us return to Boris's suggestions about Yom Kippur and Lent: that they provide vehicles for the expression and purging of individuals' unconscious guilt. While this may explain one function that they serve, we can see how-once institutionalized-they may have the further effect of reinforcing and fostering guilt in the participants of the culture, perhaps encouraging a belief that such guilt is justified and not merely based in phantasy. Recognition of this effect suggests the need to draw a distinction between situations whose symbolic meaning for an individual derives (primarily) from her projection of her internal world onto them, and those in which she is provoked into confrontation with it. (This difference is ultimately a matter of degree: In all cases of symbolization, the situation provides some grounds for bearing the symbolic significance that it does.)

For example, Hinshelwood describes the infantilizing effect that traveling by plane has on the passengers: Belted into their seats, with trays of food set in front of them, they "regress to the trusting and dependent posture of the infant strapped into a high-chair" $(1995,197)$. Similarly, it is plausible that the mass media's relentless attention, documented by feminists, to the contours of women's bodies might force to the surface an adolescent girl's unease with the adult body she feels obliged to assume. The social phenomenon that feminists point to does not tell the whole story of the psychic effect that psychoanalysts investigate, but it takes us part of the way: the "message" of the media is not identical with the adolescent's unconscious conflict, but it stirs it up.

The point does not apply only to symbolism. Social situations can equally be thought to induce processes of "splitting" in individuals, by encouraging the repudiation of parts of the self. Hinshelwood suggests that the behavior observed in Milgram's famous "electrical shock" experi- ments in the 1960s can be described in these terms: The discomfort caused by the individual's experience of dissonance between his judgments and those of the people around him leads him to surrender his capacity for moral judgment altogether, and to defer to the cruel suggestions made by the others (Hinshelwood 1997, 203-7).

Psychoanalytical treatment, Hinshelwood points out, carries a risk of splitting common to all "helping" relationships: The patient may divest himself entirely of his ability to help himself and allot himself a role in which he is utterly dependent on the analyst. However, Hinshelwood argues, psychoanalysis differs from other "advisory" situations insofar as it aims to make the patient aware of any such attempted divisions of labor within the "research project on his own mental state" that is undertaken $(1997,137)$. Thus, while it might be said that the psychoanalytic situation itself "provokes" splitting (insofar as the analyst, presenting a "blank screen," facilitates the patient's projection of his internal object relationships onto him, in an "uncontaminated" transference), this is, as it were, for "pedagogical" purposes only. The patient's transference provides the material for the analysis, which, if successful, will enable him to gain a greater knowledge, and thereby control, of his own unconscious processes. The expectation guiding the analysis is that, over time, the use of splitting in the patient will decrease as his psychic integration improves.

Why should the fact of social "provocation" be of interest to an analyst? One might object that any recognition of it will be idle: The analyst's task, that of understanding the patient's unconscious engagement with reality, remains the same whatever the nature of that reality. Suppose the revival of an unresolved conflict in a patient has been provoked: Still, it can be argued, it is the conflict that is relevant for the analysis and not the circumstances of its revival. But, at least from the therapeutic point of view, an analyst has an interest in knowing the strength of a patient's fantasies-and in this respect, there is a significant difference between a phantasy that can latch on to, and distort, almost any external situation, and one that becomes domi- 
nant in the individual's life only when reality seems to confirm it. ${ }^{7}$ The "provoked" unconscious, like an infant neglected by his mother, does not have the help afforded by a benevolent environment in distinguishing between the fantastic and the real. An analyst needs to be aware of the countervailing forces that impede her task of clarifying this distinction.

Further, insofar as an analyst conceives of her task as therapeutic, a point may be reached at which her appreciation of social etiological factors forces her to conclude that the analysis of individuals, even if it remains possible, is no longer worthwhile. In a situation where very powerful social forces militate against psychic integration, the piecemeal attention to individuals' minds will appear quixotic. In these circumstances, an analyst's skills are surely better used in understanding how social institutions are promoting "primitive" processes—splitting, regression, projective identification-in the population at large. Such an understanding would be of value in informing attempts to transform social and political reality and, in their wake, psychic reality also.

Opinion will differ, of course, about how bad things need to be before the analysis of individuals loses its point. At the extreme end of the spectrum, a population terrorized by random acts of torture seems to be a clear example of a case where political change will be a more effective means of improving psychic integration than psychoanalysis. In the western democracies in the post-war period, psychoanalysts have continued, on the whole, to confine themselves to work with individual patients. Nonetheless, they have lent their skills, occasionally, to political debate: One notable example was the participation of some, in the 1980s, in Psychoanalysts for the Prevention of Nuclear War. The members of this group shared the view that nuclear weapons were an especially dangerous resource for human beings, insofar as they made it possible for aggression and violence to be unleashed irreparably. War encourages and legitimizes our capacities for splitting and projection, and an infantile conception of the world as divided into wholly good and bad "objects" (Temperley 1989). It is an excellent example, therefore, of a situation in which the psychoanalyst's normative interest in our "internal" worlds ought to lead naturally to a concern with the external, social world.

\section{FEMinist “Literalism”}

We saw earlier that, although Klein believes that the "real" mother is an important influence on the infant's internalization of a maternal figure, she is not the only influence. Rather, the experience she provides modifies the infant's innate dispositions to phantasy: The resultant internal mother is not a simple replica of the "real" one. Some feminists who draw on psychoanalytic theory have wanted to retain the first part of this story, while dissociating themselves from the second. In particular, they reject any implication of the instincts in accounting for psychological development. In Chodorow and in Eichenbaum and Orbach, we find the suggestion that explanation in terms of "social" or "relational" factors excludes recourse to "instinctual" factors. ${ }^{8}$ This is a false opposition, at least in relation to Klein's theory, in which object-relational fantasies are precisely an expression of instinctual impulses that become modified under the weight of social experience.

Orbach's and Chodorow's descriptions of the infant's internalization of the mother differ markedly from Klein's in their "literalism": This is where, as I mentioned above, a Kleinian perspective provides grounds for criticism of theirs. They barely acknowledge the distorting effect of phantasy (which, in Klein's account, makes the internal mother potentially so dissimilar from the real mother); instead, the mother is presented as if she were a direct conduit to the social world, as if internal relationships were an accurate reflection of social ones. In her book on anorexia, Orbach presents infant daughters as passive recipients (and victims) of the messages, or taboos, relating to female behavior, that their mothers, in sexist society, convey: "[T] he mother knowingly as well as unconsciously distills the social laws" (1993, 24). In particular, the mother communicates to her daughter the idea that females must suppress their own needs. Orbach's account of the detri- 
mental effect this has on the daughter's psychological development casts her as a victim whose only wishes are legitimate desires for nurturance: "Unable to condemn the caretaker, who is still much needed, the developing person takes into itself the idea that it is not the responses of the caretaker to its needs that are inappropriate, but rather the needs ... that are causing the problem. Thus it berates itself for its needs and attempts to bury them ..." (1993, 69). This rational and wronged daughter is a far cry from the greedy, savage, and envious infant depicted by Klein. For Klein, dependence is inevitably going to be a source of difficulty because it is part of the human condition; in Orbach's presentation, such difficulty is the contingent outcome of patriarchal ideology.

Of course Klein may not be right. But her feminist critics (even those sympathetic to psychoanalysis) tend to overlook the fact that the nature of the newborn infant is an empirical question-to be settled, presumably, by evidence. Instead, Klein's hypotheses are dogmatically (and sometimes incoherently) rejected out of hand.

Moreover, even within its own terms, one can criticize the "literalist," sociologically-oriented, and functionalist psychoanalytic framework adopted by Orbach and Chodorow for its overgeneralisation. Surely a sociological perspective ought to take more account of differences between familial structures and arrangements; for example, single- versus two-parent families, the effect of having same- or opposite-sex siblings, the use of nannies or creches, and so on. ${ }^{9}$ These generalizations, in combination with the lack of differentiation between individual mothers' psychologies, result in a picture that is strangely unpsychoanalytical, and-in comparison with Kleinian theory-lacking in explanatory power. As Elizabeth Young-Bruehl remarks (in connection with Orbach's work): "A theory that equates the mother-as-person and mother-as-cultural-imperative cannot take an intrapsychic mother-a mother of a patient's phantasy-into account.... But this means ... that it is impossible to explain why one young woman develops an eating disorder and another only conforms to her mother and her culture by dieting ...” $(1993,323)$.
These feminist "translations" of psychoanalysis depict the unconscious as standing in closer, and more systematic, relations to social reality than Klein's theory allows. And the lesson to be learned from them applies, not just to feminist appropriations of psychoanalysis, but more widely: that an over-hasty concern to acknowledge the impact on individuals of the social world can lead to an unnecessarily impoverished psychology, lacking in explanatory power. ${ }^{10}$ Acknowledgement of the role of unconscious phantasy in mental life does not require us to deny that the "real" world may powerfully disturb us. ${ }^{11}$

\section{ACKNOWLEDGMENTS}

I would like to thank Sebastian Gardner, Neil Vickers, Ruth Weintraub, Jonathan Wolff, and Maria Pozzi for help with this paper.

\section{Notes}

1. I have not avoided using normative terms (disorder, illness) for psychological conditions such as anorexia. Freud conceived of psychoanalysis as a branch of medical science, and most practicing analysts continue to regard their work as therapeutic and corrective. I have left to one side, in this paper, the strand of feminist thought that rejects such normative notions (and, often, the medical/psychiatric establishment) as ideological and oppressive in themselves. For discussion of this view, see Ussher 1991, chap. 7.

2. Feminists have rightly unmasked implausible and self-serving ascriptions, made by men, of sex-differentiated traits to "nature," and have pointed instead to the social conditions that produce such differences. Another feminist worry has been that claims of commonality among women will lead to the neglect of hugely significant differences between them: a false "universalism." A third worry is that acknowledgement of an innate predisposition to, say, a certain sort of behavior amounts to "determinism," and renders any attempt to change that behavior futile. But none of these mistakes are necessitated by Klein's view.

3. Klein 1946. The Kleinian understanding of the "schizoid mechanisms"-most especially that of projective identification-has developed a great deal since Klein's seminal article. It is not necessary for my purposes here to explore these developments.

4. The application of the term Kleinian is, necessarily, a matter of degree, as most practitioners indulge in some theoretical eclecticism. It seems to me that the features I discuss in these psychoanalytical explanations can, unproblematically, be termed Kleinian. 
5. See Klein's “postscript” to her 1959 article (which records a discussion she had with an anthropologist) for a nice illustration of this direction of explanation.

6. See Ann Scott (1996, chap. 1) for an interesting discussion of how Jeffrey Masson (1984), by overlooking this point, targets his attack on Freudianism at a caricature of Freud's position.

7. For the notion of "domination," see Gardner 1993, 164-65. Reality-testing is an essential part of psychological development, as it develops the capacity to differentiate between the internal and external worlds. It follows that if an external situation does not seem to differ from the internal one, the subject is deprived of a means of putting phantasy into perspective.

8. Eichenbaum and Orbach $(1985,32)$ were quoted above. Chodorow draws a contrast between the psychoanalysts' "emphasis on the difficult libidinal path to heterosexuality" and the "relational aspects of the situation" $(1978,114)$.

9. Chodorow acknowledges that she "fudges" the issue of sexual orientation (by talking only of heterosexual couples), but her account is a good deal more abstract than that.

10. The same tendency can be observed in writings by members of the Frankfurt School and their followers. For criticisms of Marcuse's appropriation of Freud, for example, see MacIntyre 1970, chap. 4.

11. A failure to appreciate this point has marked a great deal of the discussion, critical of psychoanalysis and generated by a variety of events, that has had such media coverage during the last two decades. The abandonment by Freud of his early "seduction theory," for example, is discussed as if the theory that replaced it (invoking infantile sexual phantasy) was incompatible with the acknowledgement of any real sexual abuse. Alarm at the prevalence of childhood abuse shown by the Cleveland inquiry in Britain and allegations of cases of "False Memory Syndrome" added fuel to the debate about psychoanalysis. For discussion of these topics, see Scott (1996, passim).

\section{REFERENCES}

References to Klein's writings are to R. Money-Kyrle, ed., 1975. The Writings of Melanie Klein (London: Hogarth Press), vols. 1-4 (abbreviated here as WMK 1,2 , and so on).

Boris, H. 1984a. The problem of anorexia nervosa. International Journal of Psychoanalysis 65:315-22.

- $1984 \mathrm{~b}$. On the treatment of anorexia nervosa. International Journal of Psychoanalysis 65:435-42.

Chodorow, N. 1978. The reproduction of mothering. Berkeley and Los Angeles: University of California Press.
Dolan, B., and I. Gitzinger, eds. 1994. Why women? Gender issues and eating disorders. London: Athlone Press.

Eichenbaum, L., and S. Orbach. 1985. Understanding women. Harmondsworth, Eng.: Pelican.

Fallon, P., M. Katzman, and S. Wooley, eds. 1994. Feminist perspectives on eating disorders. New York: Guilford Press.

Fricker, M., and J. Hornsby, eds. 2000. The Cambridge companion to feminism in philosophy. Cambridge: Cambridge University Press.

Gardner, S. 1993. Irrationality and the philosophy of psychoanalysis. Cambridge: Cambridge University Press.

Gordon, R. 1990. Anorexia and bulimia: Anatomy of a social epidemic. Oxford: Blackwell.

. 1995. The social relocation of personal identity as shown by psychoanalytical observations of splitting, projection, and introjection. Philosophy, Psychiatry, o Psychology 2.3:185-204.

- 1997. Therapy or coercion: Does psychoanalysis differ from brainwashing? London: Karnac.

Klein, M. 1930. The importance of symbol-formation in the development of ego. MWK 1:219-32. - 1932. The psycho-analysis of children. MWK 2.

1946. Notes on some schizoid mechanisms. MWK 3:1-24.

. 1957. Envy and gratitude. MWK 3:176-235.

1959. Our adult world and its roots in infancy. MWK 3:247-63.

Lawrence, M. 1984. Education and identity: The social origins of anorexia. In Fed up and hungry, ed. M. Lawrence (London: Women's Press, 1987), 20725.

Lawrence, M., ed. 1987. Fed up and hungry. London: Women's Press.

MacIntyre, A. 1970. Marcuse. London: Collins.

Masson, J. Freud: The assault on truth: Freud's suppression of the seduction theory. London: Faber and Faber.

Nietzsche, F. 1994. On the genealogy of morality. Ed. K. Ansell-Pearson. Cambridge: Cambridge University Press.

Orbach, S. 1993. Hunger strike. Harmondsworth, Eng.: Penguin.

Richards, B., ed. 1984. Capitalism and infancy. London: Free Association Books.

- 1989. Crises of the self. London: Free Association Books.

Richmond, S. 2000. Feminism and psychoanalysis: Using Melanie Klein. In Feminist perspectives on eating disorders, ed. M. Fricker and J. Hornsby (New York: Guilford Press), 68-86. 
Riley, D. 1983. War in the nursery: Theories of the child and mother. London: Virago.

Robinson, S. 1984. The parent to the child. In Crises of the self, ed. B. Richards (London: Free Association Books), 167-206.

Scott, A. 1996. Real events revisited. London: Virago. Sinason, V. 1989. The psycholinguistics of discrimination. In Crises of the self, ed. B. Richards (London: Free Association Books), 217-27.

Sohn, L. 1985. Anorexic and bulimic states of mind in the psycho-analytic treatment of anorexic/bulimic patients and psychotic patients. Psychoanalytic Psychotherapy 1.2:49-56.
Stonebridge, L., and J. Phillips. 1998. Reading Melanie Klein. London: Routledge.

Temperly, J. 1989. Psychoanalysis and the threat of nuclear war. In Crises of the self, ed. B. Richards (London: Free Association Books), 259-67.

Ussher, J. M. 1991. Women's madness: Misogyny or mental illnes? London: Harvester Wheatsheaf.

Young-Bruehl, E. 1993. On feminism and psychoanalysis: In the case of anorexia nervosa. Psychoanalytical Psychology 10.3:317-30. 